The question now becomes, what is the smallest usable quantity of information? Arguably the answer is one bit. If we know that one variable is 'high' or 'low', i.e. above or below some appropriate cut-off value, then one binary unit of information will be just enough to tell us with certainty whether the other variable is 'high' or 'low'. Smaller amounts of information will also tell us this but with increasing degrees of uncertainty. On the other hand, a larger amount of information would enable us to classify the variables into three or more categories. Clearly, a two-fold classification is the crudest possible. Therefore, setting $I(x, y)$ equal to 1 and solving the equation we find $r=\frac{1}{2} \sqrt{3}=0.866$ as the smallest correlation which has even this degree of predictive power.

Some may find this result surprising. Correlations of this magnitude are rarely seen in the literature of psychiatric research or clinical psychology. This evidently means that the variables in question are not associated to any useful extent (whether for clinical decision-making purposes or for the advancement of theory). I submit that this is usually because they are 'soft', i.e. noisy and only loosely relevant estimates of the underlying variables which we would prefer to be measuring, if we knew what they were and how to measure them.

The use of vague and subjective methods of psychological 'measurement' introduces a screen of noise between the numbers which we handle statistically and the real object of study; hence the low correlations usually seen. Much more research effort must be put into developing and using more penetrating methods of identifying, defining and measuring those psychological processes, the malfunctioning of which we call 'psychopathology'. Until this is done, psychiatric research of all kinds will continue to be bogged down in futile attempts to connect increasingly sophisticated genetic, biochemical, neurophysiological and neuroanatomical 'hard' data with 'soft' clinical data, based on nebulous measurements or on diagnostic systems decided by committees.

We cannot observe mental processes directly, any more than 'hard' scientists can observe chemical kinetics or intra-atomic events directly. We shall only make solid progress as they have done, by formulating hypotheses unambiguously and in language which allows mathematics to be used to derive experimentally testable predictions. This 'mathematical modelling' approach demands some mental effort, but it does yield solid results and after all, it would be rather foolish to imagine that we could ever establish a science of the mind without exerting our own.
PINSKER, M. S. (1964) Information and Information Stability of Random Variables and Processes (Transl. A. Feinstein). San Francisco: Holden-Day.

Middlewood Hospital

Hugh B. G. Thomas

Sheffield S6 ITP

\section{Reading about transcultural psychiatry}

SIR: Professor Cox gives the reader an excellent start to reading the literature on transcultural psychiatry. He hints that it might however be limited since "The choice of books inevitably reflects my own clinical and academic interests, and the volumes received from the review editor of this Journal over recent years". "Recent years" is significant. His view reflects his own era. There was an era before that to which I was witness. At that time, E. D. Wittkower was regarded as the initiator. When it came to inviting an author on "transcultural psychiatry" for Modern Perspectives in World Psychiatry as long ago as 1968, I turned automatically to Wittkower who presented a scholarly review of the field. What Wittkower originated, Murphy carried on with great zest and effort; I would not wish to diminish his massive contribution in any way.

WrrtKower, E. D. (1968) Transcultural psychiatry. In Modern Perspectives in World Psychiatry (ed. J. G. Howells). Edinburgh: Oliver \& Boyd

Hill House

J. G. Howells

Higham

Colchester CO7 6LD

Early cortical tactile-evoked potentials, laterality and schizophrenia

SIR: Allen et al (Journal, April 1991, 158, 529-533) have repeated with differing results an earlier study of Cooper et al (1985) in which the ipsilateral and contralateral cortical potentials evoked by vibrotactile stimulation of the finger were compared. While their attempt to reproduce faithfully the experimental conditions used by Cooper et al is to be applauded, their paper raises a number of important general issues in relation to the interpretation of data from electrophysiological experiments in psychiatric patients (e.g. Cooper, 1985; Tress et al, 1983).

In their report, the authors make the extraordinary statement that conventional nomenclature was not used to describe their traces because "reporting results became too complicated owing to different latencies in different subject groups" (p. 530). They give mean latency values of certain responses using their own system of nomenclature. It is precisely 
because latencies may vary between subject groups that consistent nomenclature is essential. Evoked potentials are conventionally identified according to the polarity and modal latency of their peaks. Thus when potentials from patients and normal subjects are compared, like is compared with like, and changes in the characteristics of the potentials may be related to changes in the processes or structures generating them. Unfortunately, when the present results are quoted by future authors, confusion will arise. For instance, it would seem reasonable to suppose that in a paper on early cortical-evoked potentials, the wave labelled N1 (their Fig. 1) would refer to the initial negative-going cortical potential (which is conventionally called $\mathrm{N} 19$ or $\mathrm{N} 20$ since its modal latency is about $20 \mathrm{~ms}$ ). A peak corresponding to $\mathrm{N} 20$ is clearly present in Fig. 1 but is unlabelled and distinct from the peak labelled N1.

The authors note considerable variability both within and between subjects in the amplitudes of their cortical potentials. At least some of this variability is likely to arise from the type of stimulus used. Vibrotactile stimulation of the skin of the finger may excite impulses in a wide range of sensory fibres of differing conduction velocities (Iggo, 1982); together with the $10 \mathrm{~ms}$ duration of the stimulus this produces a diffuse and temporally dispersed afferent volley. Furthermore, spread of vibration is a potent stimulus to muscle receptors of the intrinsic muscles of the hand and forearm (Davies, 1987). Since the amplitude of excursion of the vibrator is not quoted in their paper, the extent of these effects cannot be assessed.

Finally, a further source of variability might arise from combining data from patients suffering different forms of schizophrenic illness. Until proved otherwise, it should not be assumed that sensory processing or its dysfunction is similar in acute $v$. chronic patients, or in those with positive v. negative symptoms.

COOPER, J. E., ANDrews, H. \& BArber, C. (1985) Stable abnormalities in the lateralisation of early cortical somatosensory evoked potentials in schizophrenic patients. British Journal of Psychiatry, 146, 585-593.

DAviEs, T. W. (1987) Contribution from hand muscle afferents to forearm muscle stretch reflexes in man. Journal of Physiology, 390, 258.

IGGo, A. (1982) Cutaneous sensory mechanisms. In The Senses (eds H. B. Barlow \& J. D. Mollon), pp. 369-408. Cambridge: Cambridge University Press.

Tress, K. H., Caudrey, D. J. \& Merta, B. (1983) Tactile-evoked potentials in schizophrenia. Interhemispheric transfer and drug effects. British Journal of Psychiatry, 143, 156-164.

Bexley Hospital

TEIFION DAviES

Old Bexley Lane

Bexley, Kent DA5 2BW

\section{Clozapine in patients with NMS}

SIR: Szabadi \& Cashman (Journal, April 1991, 158, 577) suggest that clozapine is the drug to consider when a patient has suffered neuroleptic malignant syndrome (NMS). However, it would be inappropriate to generalise their experience with clozapine to other patients who have suffered NMS. The first case report linking clozapine (in combination with lithium) to NMS appeared more than four years ago (Pope et al, 1986). This was followed by another case in which NMS was presumed to have resulted from a combination of clozapine and carbamazepine (Muller et al, 1988). There might have been some scepticism about these reports as clozapine by itself could not be implicated. More recently, a series of case reports suggested that clozapine alone can cause NMS (e.g. DasGupta \& Young, 1991). It would not be unfair to say that the strategy suggested by Szabadi \& Cashman (1991) has also been adopted in the past without recurrence of NMS. Despite its different structure and pharmacological profile, clozapine does affect the dopaminergic system; recently the gene for a human dopamine D4 receptor with high affinity for clozapine has been cloned (Van Tol et al, 1991). In view of these observations it may be rather premature to generalise about the potential safety of clozapine in patients with NMS who need further antipsychotic treatment.

DAsGuPTA, K. \& Young, A. (1991) Clozapine-induced neuroleptic malignant syndrome. Journal of Clinical Psychiatry, 52, 105-107. MULlER, T., BECKER, T. \& FritzE, J. (1988) Neuroleptic malignant syndrome plus carbamazepine. Lancet, 31, 1499-1500.

POPE, H. G., COLE, J. O., ChORAs, P. T., et al (1986) Apparent neuroleptic malignant syndrome with clozapine and lithium. Journal of Nervous and Mental Diseases, 174, 493-495.

Van Tol, H. H. M., Bunzow, J. R., Guan, H. C. el al (1991) Cloning of the gene for a human dopamine D4 receptor with high affinity for the antipsychotic clozapine. Nature, 350, 610-614.

The Maudsley Hospital

AdityanjeE

Denmark Hill

London SES 8 AZ

\section{Outcome indicators in mental handicap}

SIR: We read with interest Jenkins' article (Journal, October 1990,157,500-514), particularly on outcome indicators for mental handicap. Although we fully agree there is an urgent need for specific outcome indicators for mental health care, we were dismayed to see that many of the suggested indicators for mental handicap bore little relationship to the clinical practice of the 'psychiatry of mental handicap'. Many indicators given seemed to be more related to the clinical practices of obstetrics, paediatrics, 